\title{
Learning Mole Concept with PALS: An Intervention for Working Students in a Night School
}

\author{
Jeniffer C. Taborada ${ }^{1 *}$, Joje Mar P. Sanchez ${ }^{2}$ \\ ${ }^{1}$ Night Department, Ramon Duterte Memorial National High School, V. Rama Avenue, Cebu City, Philippines \\ ${ }^{2}$ College of Teacher Education, Cebu Normal University, Osmeña Boulevard, Cebu City, Philippines
}

*Author to whom correspondence should be addressed; email: jeniffer.taborada@gmail.com

\begin{abstract}
A quasi-experimental study was done in order to investigate the effectiveness of Peer-Assisted Learning Strategy (PALS) as an intervention in learning Mole Concept for the ninth grade-working students in a night school in Cebu City, Philippines. Study findings revealed that students exposed to conventional lecture method (CLM) $(\mathrm{N}=15)$ had Below Average performance in the pre/posttests, and those exposed to PALS $(\mathrm{N}=15)$ had Below Average performance in the pretest and Average performance in the posttest. Both groups had significant mean improvement before and after exposure to CLM $(t=5.07, \mathrm{p}=.000)$ and PALS $(t=10.37, \mathrm{p}=.000)$, indicating that both lectures and peer tutoring are essential in teaching-learning process. The study also found out that those exposed to PALS ( $t=4.24, \mathrm{p}=.000$ ) had significantly greater improvement than those exposed to CLM. Moreover, sex, age, civil status and number of people in the house were not associated with their performance in Chemistry, implying that these profiles do not affect the tutortutee relationship. The study concluded that PALS manifested a more enhanced performance among the working students in Chemistry.
\end{abstract}

Keywords: Peer-assisted learning strategy; Conventional lecture method; Mole concept; Working students

\section{INTRODUCTION}

Science is frequently perceived to be of great importance because of its link to technology and industry, which are areas with high priority for development. As such, it is included as a core subject in both elementary and secondary curricula to make the youth achieve a degree of "scientific learning". However, many of the Filipino students are not attaining functional literacy to keep pace or meet the challenges of the rapidly changing world. This is evident in the unsatisfactory results revealed in the 2003 Trends in Mathematics and Science Survey (TIMSS) and 2019 Programme for International Student Assessment (PISA) that proved that vast majority of Filipino students performed way below the levels of most students from other countries in international tests (Dela Cruz, 2012; Organization for Economic Co-operation and Development, 
2019). Thus, this alarming poor performance calls for educational managers to focus their attention on reforming and delivering quality instruction. Likewise, students in basic education need to be provided with maximum opportunities to become functionally literate in science, including those who work and study at the same time.

Working students work and study at the same time and are often enrolled in night schools in the community. In the past school year, working students constitute approximately $30 \%$ of the enrolment in the night school in Cebu City. Of these students, $40 \%$ of them were often late, $20 \%$ had absences due to the demands of their job, and an alarming $10 \%$ failed that they need to take summer remediation classes to comply the pre-requisites of the succeeding curricular grade level (Ramon Duterte Memorial National High School, 2017). In view of these scenarios, the academic community intensified its action to provide intervention and remediation programs to cater to the needs of the students in science, particularly in Chemistry. In Chemistry, the mole concept has been one of the most difficult topics to teach and learn (Furio, Azcona, Guisasola, \& Ratcliffe, 2000). According to the study of Furio, Azcona, and Guisasola (2002), students showed great difficulty in handling the topics in mole concept, and pointed out the need to review the instructional methods used in schools. With this, there is a need to use a remediation program that would integrate an instructional method to enhance the working students' understanding of mole concept.

One of these remediation programs considered by the school to help the working students in improving their performance in Chemistry was the use of cooperative learning. Cooperative learning is a teaching arrangement that uses small groups so that students can work together to maximize each other's learning, where positive interdependence, individual accountability and face-to-face promotive interaction are present (Johnson, Johnson, \& Smith, 2013). In such learning environment, students work together to learn and become responsible for their own as well as their teammates' learning. The achievements and their interpersonal relationships have been found to improve in such a learning environment (Dotson, 2001).

One related strategy of cooperative learning is the use of peer tutoring in instruction. Peer tutoring is a process by which students, with the guidance from their teacher, help by teaching one or more peers to learn skills or concepts (Golding, Facey-Shaw, \& Tennant, 2006) while accommodating a classroom with diverse learners to improve academic achievement across ability levels and content areas (Okilwa \& Shelby, 2010). Due to this, several studies were conducted to determine the effectiveness of such strategy in the teaching of science concepts. Ayuba (2011), Jibrin and Zayum (2012) and Ezenwosu and Nworgu (2013) reported that peer tutoring has enhanced academic achievement of students in Biology.

Kapil and Malini (2018) enumerated the models relating to peer tutoring, namely class wide, crossage, reciprocal peer, same-age, and peer assisted learning strategy (PALS). In PALS, the teacher pairs students who need help or additional instruction where their peers can assist. Specifically, they support each other's learning rather than relying solely to an adult teacher. Pairs of students interact to assist each other's academic achievement, wherein one student adopts the role of the tutor, while the other the role of the tutee.

With this background, the present study was conducted in aiming to investigate the effects of PALS on the performance of working ninth grade students in Chemistry, especially on the topics of Mole Concept. Specifically, the study aimed to determine the students' pretest and posttest performance levels exposed to PALS and the conventional lecture method (CLM), determine whether there was significant improvement before and after exposure to such methods, compare the mean gains brought about by the two methods, and check if there were significant relationships 
that exist between the students' performances and their profiles. This could address the decreasing performance of the working students in night schools in the city, thus, the conduct of the study.

\section{METHODS}

Research Design. The study utilized a quasi-experimental method of research in which pretestposttest with control group design was employed in order to determine the effectiveness of PALS in teaching mole concept to high school working students. Quasi-experimental design has the rigors of true experimental designs but lack random assignment of participants (Rogers \& Révész, 2019), and was appropriate for the study because of the purposive sampling of working students in the night school.

Research Environment and Participants. The study was conducted in the night department of a public school in Cebu City, Philippines, where a greater number of working students are enrolled. Through purposive sampling, thirty working students in the $9^{\text {th }}$ grade participated in the study. They were divided into two groups with 15 participants each: the control group was exposed to CLM, where there was no peer tutoring and the teacher was the lecturer. The experimental group was exposed to PALS, where the identified participants (called tutees) were paired with their performing classmates (called tutors). The two groups have comparable Chemistry ability based on their pretest scores $(t=0.09, \mathrm{p}=.906)$.

The demographic profile of the two groups is presented in Table 1 below.

Table 1. Demographic profile of Grade 9 working students

\begin{tabular}{|c|c|c|c|c|}
\hline \multirow{2}{*}{ Profile } & \multicolumn{2}{|c|}{ Control Group } & \multicolumn{2}{|c|}{ Experimental Group } \\
\hline & $\mathrm{f}$ & $\%$ & $\mathrm{f}$ & $\%$ \\
\hline \multicolumn{5}{|l|}{ Sex } \\
\hline - Male & 12 & $80 \%$ & 10 & $67 \%$ \\
\hline - Female & 3 & $20 \%$ & 5 & $33 \%$ \\
\hline \multicolumn{5}{|l|}{ Age } \\
\hline - 13-15 & 5 & $33 \%$ & 4 & $27 \%$ \\
\hline - $16-18$ & 7 & $47 \%$ & 5 & $33 \%$ \\
\hline - $19-21$ & 2 & $13 \%$ & 5 & $33 \%$ \\
\hline - $22-24$ & 1 & $7 \%$ & 1 & $7 \%$ \\
\hline \multicolumn{5}{|l|}{ Civil Status } \\
\hline - Single & 14 & $93 \%$ & 13 & $87 \%$ \\
\hline - Married & 1 & $7 \%$ & 2 & $13 \%$ \\
\hline \multicolumn{5}{|c|}{ No. of People living in the House } \\
\hline - $3-7$ & 11 & $73 \%$ & 8 & $53 \%$ \\
\hline - $8-12$ & 2 & $13 \%$ & 6 & $40 \%$ \\
\hline - $19-21$ & 1 & $7 \%$ & 1 & $7 \%$ \\
\hline - $22-24$ & 1 & $7 \%$ & 0 & 0 \\
\hline
\end{tabular}

Based on Table 1, most of the student participants were males as there were more male working students in the night school. Most of the participants were in basic education school age (13-18 years) and some were beyond such age (more than 18 years); this variety of ages is rampant in night school. Moreover, most of them were single and only a few were married. Lastly, these working students usually live in a house of 3-7 people, while the remaining ones in live in extended families. 
Research Pedagogies and Instruments. The study used two pedagogies: CLM for the control group and PALS for the experimental group. The former was a teacher-directed instruction where activities were carefully structured and delivered by the teacher (the lecturer) in order to maximize student learning, while the latter was student-driven instruction where activities were planned by the teacher but done by the students through peer tutoring-the tutor assisted the tutees in learning the Mole Concept in Chemistry.

In PALS, the teacher gives the topic beforehand to the tutors in order to have time to study the lesson. During the implementation of the lesson, the teacher gives preliminary activities and/or sample scenarios and problems to illustrate what the lesson is all about; in this step, the tutors may ask questions for clarification regarding the topic. Afterwards, the tutors go to their assigned tutees and conduct peer tutoring. In this process, the tutee reads statements about mole concepts, and tells the tutor what he understands about it. The tutor then affirms or critiques what the tutee understands, and guides the tutee towards attainment of the competency through question-andresponse strategy. In the case of problem solving, the tutee reads first the problem and gives what is/are given and asked, then the tutor affirms or negates the answer; if the given and asked are not correct, then the tutor guides the tutee to obtain the correct answers. This strategy runs same with choosing of the formula, writing the solution, and stating the answer of the problem. Throughout the process, the tutor assists the tutee, hence the name peer-assisted learning strategy.

Two instruments were used by the study. The first one is the students' profile sheet that provides data concerning the personal background of the participants such as sex, age, and civil status. The second tool is the validated pretest/posttest that has twenty items focusing on the understanding of the Mole Concept. Three experts validated the research tools.

Data Gathering Procedures and Data Analysis. Research permissions were asked first before the conduct of the study. The permissions were asked from the Schools Division Superintendent of Cebu City and the school principal of the night school, as well as informed consent from the participants.

Pretesting was then administered to the working students to get their performance level before the topic on mole concept was taken up. After the pretesting, the students were exposed to two pedagogical approaches, namely CLM while the other with PALS during the second quarter of the school year: the former was given to the control group, while the latter was given to the experimental group. Mole Concept topics such as the definition of mole, use of mole in chemical equations, mole conversions, and some applications of mole concept towards the environment were covered during the one-month experimentation. Posttesting was then administered to both groups in order to determine their performance level after the topic on mole concept was taken up.

The data obtained from the conduct of the study were analyzed using $t$-testing ( $t$-tests for small and single samples, dependent samples, and two independent samples) and correlational analysis (Pearson $r$ analysis). All tests were conducted at 1\% level of significance.

Ethical Considerations. The researchers ask permission from the division superintendent and school principal to conduct the present study in the night school. Afterwards, informed consent was asked from the study participants. All names remained anonymous while data obtained from the study were kept confidential and private. 


\section{RESULTS AND DISCUSSION}

Performance Level of the Working Students in Chemistry. Table 2 reveals the performance level of $9^{\text {th }}$ grade working students in Mole Concept in the pretest and posttest.

Table 2. Performance Levels of the Working Students in Chemistry

\begin{tabular}{llrrrrl}
\hline Test & Group $^{1}$ & Mean & SD & tvalue $^{2}$ & p-value & Description \\
\hline \multirow{2}{*}{ Pretest } & CLM & 5.93 & 1.67 & $-14.08^{* * *}$ & .000 & Below Average \\
& PALS & 5.87 & 1.96 & $-12.13^{* * *}$ & .000 & Below Average \\
\multirow{2}{*}{ Posttest } & CLM & 8.40 & 2.26 & $-6.17^{* * *}$ & .000 & Below Average \\
& PALS & 11.4 & 2.56 & $-0.91^{\text {ns }}$ & .379 & Average \\
\hline
\end{tabular}

${ }^{1} \mathrm{~N}=15$ per group

${ }^{2}$ Hypothetical mean: $60 \%$ of total score $=12$

*** Highly significant, ${ }^{\text {ns }}$ Not significant

As revealed in Table 2, the performance level in Mole Concept from both CLM and PALS groups are significantly lower than the standard set by the Department of Education. This low performance implies that the students had low knowledge on the topics as shown in the pretest, understandably because the lesson on Mole Concept was not yet introduced to them.

In the posttest, the CLM group had Below Average performance while the PALS group had Average performance. The average performance of the latter group supported Goodland (1999) as cited by Clarkson \& Luca (2002) who stated that students who were tutored found lessons more interesting, easier to follow, more enjoyable, and seemed to learn more.

Mean Improvement of the Students' Performances in Chemistry from Pretest to Posttest. Table 3 shows the mean gains of the CLM and PALS groups from pretest to the posttest.

Table 3. Mean improvement of students' performances from pretest to posttest

\begin{tabular}{lrrrrr}
\hline Group & Pretest Mean & Posttest Mean & Difference & $\boldsymbol{t}$-value & p-value \\
\hline CLM & 5.93 & 8.40 & 2.47 & $5.07 * * *$ & .000 \\
PALS & 5.87 & 11.4 & 5.53 & $10.37^{* * *}$ & .000 \\
\hline
\end{tabular}

*** Highly significant

As shown in Table 3, both groups had significantly higher posttest scores than the pretest scores, thus, gaining significant improvement in their performance. These significant mean improvements were due to students' acquiring concepts and skills about the Mole Concept brought about by exposure to CLM and PALS. CLM has helped the students to attain enhanced learning due to the active involvement of the teacher, which made students understand the concept.

The use of PALS resulted to significant improvement because the students were peer-taught than self-taught during the learning exercises they had during the course of the study. This supported the study of Ayuba (2011) who reported that significant improvement caused by peer tutoring contributed to the fact that students were actively involved in the learning process. It was clearly exhibited by both tutors and tutees that they found ways how to make learning easy and enjoyable as they actively engaged in the understanding of the mole concept. 
Comparison of the Mean Gains in Chemistry between CLM and PALS Groups. Table 4 compares the mean gains between the control and experimental groups.

Table 4. Differences between the mean gains of CLM and PALS groups

\begin{tabular}{lcccc}
\hline Group & Mean Gain & Difference between Means & t-value & p-value \\
\hline CLM & 2.47 & 3.06 & $4.25^{* * *}$ & .000 \\
PALS & 5.87 & & & \\
\hline
\end{tabular}

*** Highly significant

As compared in Table 4, there was a highly significant difference between the mean gains of CLM and PALS groups. The use of PALS was more effective in improving the performance of students in Chemistry compared to the group conventionally taught without peer tutoring. This denoted that both peer tutors and their tutees were directly involved in an active, friendly and individualized learning process, as they supplemented what the teacher taught to them.

These results supported Goodland and Hirst's (1989) assertion that both peer tutors and their tutees gained significant gains. Literature, which stated that those with peer tutors performed better on higher order conceptual understanding scales than students who read the material simply for individual study purposes, was supported (Clarkson \& Luca, 2002). Moreover, the results supported the study of Ezenwosu \& Nworgu (2013), which asserted that the superior achievement of peer tutoring over the conventional ones was attributed to the fact that it gave students the opportunity to explain their thought process in such a way that the other students would understand. The effective characteristic of peer tutoring affirmed the theory of Vygotsky which emphasized the role of the students to generate learning where students coached peers through social interaction. Learning came about through social negotiation within a cultural context (Clarkson and Luca, 2002).

Furthermore, the results also verified the premises of cooperative learning asserted by Johnson \& Johnson (2016). These premises include the cooperation among students who work together to accomplish goals, just as peer tutors and tutees worked together, in order to achieve the competencies specifically needed in understanding mole concept. Johnson \& Johnson (2016) also asserted that within cooperative situations, individuals sought outcomes that were beneficial to themselves and beneficial to all other group members. Ultimately, cooperative learning maximized learning through the use of small groups, which was done in the peer tutoring strategy.

Relationships between PALS Group's Performance and the Students' Profiles. Being able to interact with peers as tutors or tutees may be attributed to some profiles of the students exposed to PALS. Table 5 reflects the relationships between the students' profiles and their performance in the PALS group.

Table 5. Relationship between PALS group's performance and students' profile

\begin{tabular}{lrr}
\hline Profile vs. Students' Performance & r-value & p-value \\
\hline Sex & $0.02^{\text {ns }}$ & .933 \\
Age & $0.27^{\text {ns }}$ & .327 \\
Civil Status & $-0.20^{\text {ns }}$ & .468 \\
No. of people living in the house & $-0.07^{\text {ns }}$ & .810 \\
\hline \multicolumn{2}{c}{ ns Not significant }
\end{tabular}


As reflected in Table 5, selected profiles were not significantly correlated with the students' performance when they were exposed to PALS. This means that sex, age, civil status, and number of people in the household do not determine the extent of the effect of PALS to the mean improvement of students' performance. This may also mean that such profiles are not pre-requisite to being tutors or tutees in the peer tutoring process. For example, tutors may be male or female in the peer tutoring process as sex is not a determinant for being good tutors, and these tutors may help any student since sex is not a determinant of good tutees. Tutors and tutees are not determined by sex and other profiles (age, civil status and number of people in the household) and can be involved in the peer tutoring process regardless of such profiles.

\section{IMPLICATIONS TO CLASSROOM PRACTICE}

The study showed that the use of peer tutoring strategies, especially PALS, is helpful in improving students' performance in chemical concepts such as the mole concept. The findings of the study have implications to the classroom practice of Chemistry teachers and Science instructors in general. Teachers should be mindful of the potentials of the students, and may use such potentials in enhancing the performance level of the whole class. Students with these potentials can assist other students who need help through peer tutoring. This peer learning helps tutors to develop a sense of personal efficacy, gain insight into the teaching-learning process, and discover meaningful applications of the subject matter (Goodland and Hirst, 1989). The tutees also benefit from this collaborative endeavor. They are given individualized instruction, have more contact time with their classmates, have the opportunity to discuss the subject at hand, and ask questions in a nonthreatening and supportive setting and provided interaction with peers (Reed College, 2016). Therefore, students' performance, tutor-tutee relationship and class bond are improved.

Moreover, the use of peer tutoring has given the students to interact according to their age and social context. The tutees are given the chance to talk what they think and understand about the given concept, while the tutors are given the opportunity to explain and guide their classmates towards attainment of competency (Ezenwosu and Nworgu, 2013). In this way, instruction becomes individualized, collaborative and student-centered. In order to achieve the aims of peer learning, teachers should properly select the tutors, strategically choose the tutor-tutee pairs, and consider time, difficulty, and context in designing the lessons.

Furthermore, the findings also imply that students who are well inclined with science and have the potential to assist their classmates can be tutors. Teachers should avoid subjectivity in selecting tutors and have objectivity in pairing these tutors to their classmates. They should consider maximum instructional learning while the students improve their relationship inside the classroom. With this, the learning environment becomes engaging, contextualized, and sensitive.

\section{CONCLUSIONS AND RECOMMENDATIONS}

The use of Peer-Assisted Learning Strategy was an effective intervention for the ninth grade working students of a night school as seen in the change of students' qualitative performance from Below Average to Average, significant improvement of students' performance levels after the intervention, and the significantly higher mean gain among the students than those who were exposed to convention method. Therefore, the students exposed to PALS manifested a more enhanced performance in learning the Mole Concept. Vygotsky's and Johnson \& Johnson's theories, which both stated that when peers (tutees and tutors) worked together to achieve their goals would translate to students achieving optimal learning, were affirmed in this study.

The study recommended that teachers must use peer tutoring strategy as a form of remediation program of the working students enrolled in night high schools, that Chemistry teachers utilize 
peer tutoring strategy in addition to other strategies already employed in teaching, that peer tutoring be used by other subject areas where low performance of students are observed, and that further studies on peer tutoring be conducted using large number of students as subjects in other science disciplines.

\section{REFERENCES}

Ayuba B. Impact of peer tutoring on the academic achievement on Science among secondary school students within Bauchi Metropolic. [dissertation]. [Bauchi]: Abubakar Tafawa University. 2011

Clarkson B, Luca J. Promoting student learning through peer-tutoring- a case study. [Internet]. 2002 [cited $2020 \quad$ Jan]. Available from http:/ / ro.ecu.edu.au/cgi/viewcontent.cgi?article $=4913 \&$ context $=$ ecuworks

dela Cruz RS. The science dilemma in Philippine schools [Internet]. 2012. Available from http:/ /www.science.ph/full_story.php?type $=$ News\&key=6602:thescience-dilemma-in$\% 20$ philippine-schools

Dotson, J. Cooperative learning structures can increase student achievement. [Internet]. 2001 [cited $2020 \quad$ Jan]. Available from http://www.kaganonline.com/free_articles/research_and_rationale/increase_achievement.php.

Ezenwosu SU, Nworgu LN. Efficacy of peer tutoring and gender on students' achievement in Biology. Int J Sci Eng Res. 2013; 4(12)

Furió C, Azcuna R, Guisasola J. The learning and teaching of the concepts 'amount of substance' and 'mole': A review of the literature. Chem Educ Res Prac Eur. 2002; 3(3):277-292. doi: 10.1039/B2RP90023H

Furió C, Azcuna R, Guisasola J, Ratcliffe M. Difficulties in teaching the concepts 'amount of substance' and 'mole'. Int J Sci Educ. 2000; 22(12):1285-1304. doi: 10.1080/095006900750036262

Golding P, Facey-Shaw L, Tennant P. Effects of Peer Tutoring, Attitude and Personality on Academic Performance of First Year Introductory Programming Students. FIE 2006 : proceedings : Frontiers in Education, 36th Annual Conference, Sheraton San Diego Hotel and Marina (October 2006); 2006

Goodland S, Hirst B. Peer Tutoring. A Guide to Learning by Teaching. England: Kogan Page Ltd.; 1989

Jibrin A, Zayum S. Effects of peer tutoring instructional method on the academic achievement in Biology among secondary school students in Zaria Metropolis, Nigeria. J Res Educ Soc. 2012; 3(2):13-17

Johnson D, Johnson R. An overview of cooperative learning. [nternet]. 2016 [cited 2020 Jan]. Available from http://www.co-operation.org/what-is-cooperative-learning/.

Johnson D, Johnson R, Smith K. Cooperative learning: Improving university instruction by basic practice on validated theory. J Exc Univ Teach. 2013; 25(3\&4):85-118

Kapil Y, Malini JS. Peer tutoring, an instructional strategy: A systematic approach. Sch Res J Hum Sci Engl Lang. 2018; 6(27):7792-7798 
Okilwa NSA, Shelby L. The effects of peer tutoring on academic performance of students with disabilities in Grades 6 through 12: A synthesis of the literature. Remedial Spec Educ. 2010; 31(6):450-463. doi: 10.1177/0741932509355991

Organization for Economic Co-operation and Development. Results from PISA 2018Philippines. [Internet]. 2019 [cited 2020 Jan]. Available from https://www.oecd.org/pisa/publications/PISA2018_CN_PHL.pdf

Ramon Duterte Memorial National High School. RDMNHS School Monitoring, Evaluation and Adjustment (SMEA). [Unpublished school report]. Ramon Duterte Memorial National High School, Division of Cebu City. 2017

Reed College. Current research: Is peer tutoring effective? [Internet]. 2016 [cited Jan 2020]. Available from http://www.reed.edu/nsfaire/nsfaire_sciencePsych4.html

Rogers J, Révész A. Experimental and quasi-experimental designs. The Routledge Handbook of Research Methods in Applied Linguistics. 2019; 133-143 